\title{
Seeking a unified urban systems theory
}

\author{
D. Coelho \& M. Ruth \\ School of Public Policy, University of Maryland, College Park, USA
}

\begin{abstract}
Cities are a key driver of environmental and climatic change, and at the same time significantly impacted by that change. Vulnerability varies spatially and over time, and the complex relationships among climate, ecosystem health, and socioeconomic development call for an integrated theoretical framework within which to study the world's cities. Advances in the fields of industrial ecology, urban metabolism and urban ecology shed light on these relationships. However, much of the current research is found in the form of case studies. Though detailed and relevant, the lack of a cohesive theory precludes standardization of and comparison between methodical experiments pertaining to the relationship between urban systems and global climate change. Aiming to identify and connect underlying issues, and to drive research forward, this study is a synthesis of key emergent theories and continuities in the body of research surrounding urban systems and global change. Thinking of cities as complex open systems integrated within a larger environmental and social context brings us closer to understanding how cities impact/are impacted by climate change and variability. The physical realism and interdisciplinary nature of a unified urban systems theory will facilitate more grounded and effective policy to shape and govern our cities.
\end{abstract}

Keywords: urban ecology, industrial ecology, urban metabolism, complex systems, climate change.

\section{Introduction}

Cities are a major element of the modern landscape, and as such are impacted by and are sources of significant environmental change, most notably air and water pollution, loss of habitat and biological diversity and global climate change. In 2000,47 percent of the world's population lived in urban areas [1]. This figure is higher in developed countries, but most of the population growth and 
urbanization over the next 50-100 years is expected in developing countries. By 2030 it is projected that 60 percent of the world's population will live in cities [1], many with populations exceeding half a million people [2]. Very large cities will also become more numerous. In 2000, there were 41 cities with populations greater than five million people; the projection for 2015 is 59 such megacities, 48 in developing countries [1]. And although urban areas cover only 1-6 percent of the global landscape they exert tremendous pressure on the environment beyond their borders (see Alberti et al [3] for a review of these impacts).

What is less well understood is how and how much cities interact with the environment. Urban areas are the loci of human economies and the majority of our productive and consumptive activities. The extent and nature of a city's impact on the local and global environment are defined by spatial arrangements as well as cultural characteristics that govern patterns of production and consumption. As a result, urban policies have direct and indirect impacts on the amount and quality of energy and material extracted from, and returned to, the earth system. Consider this example, much of the predicted stress on future water supply comes from population growth and changes in demand related to intensity of use directly, rather than changes in supply caused by climate change [4]. However, population growth, consumption patterns and related urban policies to control distribution will impact the local environment, climate and the city over the longer term in unpredictable ways. Similarly with residential energy use, geographic patterns of suburban development in the US are correlated with household energy demand. More compact urban areas demand less energy per capita than more sprawling areas [5]. The decision to extend municipal services into previously undeveloped areas will decrease the density of an urban area, and increase its physical and energy footprint. Conversely, encouraging more compact settlements can increase energy efficiency. Broadly, urban form and economic activity influence regional precipitation patterns and temperature (largely via urban heat islands), energy demand and the infrastructure necessary to generate and deliver it [6]. So if we would desire to deliver water and energy to urban residents in the future, the design and management of cities matters.

To answer how and how much cities interact with the environment-locally and globally-requires integration of insights from the natural, engineering, social and health sciences as well as active dialog between scientists and policy makers. Research in the growing fields of industrial ecology, urban metabolism and urban ecology — as well as complex systems theory — is actively making the necessary connections. Through analogy, metaphor and direct application, researchers are taking an "ecosystem approach" to studying natural, economic, urban and industrial systems. This approach is both relevant and appropriate to the study of sustainable urban development because it provides a flexible framework, one responsive to issues of scale and changing social and environmental conditions over time, within which to study urban systems.

\section{Cities as complex social-ecological systems}

What does it mean to take an ecosystem approach to the study of ecology and/or society? Broadly considered, an ecosystem has no pre-determined scale or 
boundaries and is instead defined as the interaction between organisms and their environment [7]. Its boundaries are drawn in order to answer a specific question. In this sense an ecosystem is a dynamic concept - rather than a physical entitytaking into account many interactions that vary over time. This approach naturally lends itself to defining hierarchical or nested systems, which are characterized by elements interacting horizontally with each other and vertically with larger organizing structures. Cities, like natural ecosystems, can be characterized as complex open systems $[8,9]$ and may dominate or be more equal parts of a larger network of other urban areas [10]. Alberti et al [3] extend that globally and, certainly at regional scales, environments are humandominated and the study of social-ecological systems is necessary to accurately describe social and ecological processes.

These social-ecological systems are self-organizing and can be thought of in terms of resilience (adaptability) and transformability (ability to fundamentally change state) [11]. According to Levin [12] a complex adaptive system is that in which "patterns at higher levels emerge from localized interactions and selection processes acting at lower levels." This is true of ecosystems, and also the economy, where the actions of individuals are made with intent, but "self organize" into larger patterns that do not embody the same intent $[3,10,11]$. These systems are dependent upon history and relationships among elements which often are time-lagged and non-linear [12]. As recipients of energy flows, complex adaptive systems naturally go through phases of organization: exploitation/growth, conservation, release and reorganization $[8,9]$. The larger the reach and complexity of the system, the greater the uncertainties and risks associated with individual actions. Insufficient efforts have been taken to model complex dynamics at the global [13] and more local scales.

Though a legitimate challenge, researchers such as Alberti et al [3] see the opportunity to finally link ecological and social sciences in the study of cities as emergent phenomena embedded within a spatial and historical context of interacting processes. If we approach cities as social-ecological systems we must embrace change and evolution. There is no single optimal state towards which we may strive $[11,14]$ and planning for maintenance or avoidance of change seems unrealistic, and even dangerous. Rather we anticipate change and plan for resilience - the degree to which a system can undergo change and retain its major organization and functioning - and build it into our cities [3, 11]. Here the goal becomes maintaining the social-ecological system's ability to evolve and develop.

\section{Lessons from theory and practice}

Taking an integrated and comprehensive approach to the study of socialecological systems is difficult and, indeed, just developing. However, lessons from industrial ecology, urban metabolism and urban ecology help to flesh out the reasoning behind focusing our attention on cities, and how to apply a complex systems or ecosystem approach to both research and policy making. Separately, all three are exploring methods of measuring human impacts on the 
environment, and to varying degrees attempting to link social and natural systems. Opportunities and challenges for integration will be discussed in the following section.

\subsection{Industrial ecology}

Industrial ecology is the systematic analysis and design of human activities and the environment with the implicit goal of optimizing the total industrial cycle: from raw material input through the creating of a finished product to waste output and back to the economy [15]. This is driven by a realization that, like cities, industrial processes are not isolated from their surroundings, but rather part of a more integrated whole, and as such influence and are influenced by their surroundings $[15,16]$. Through mimicking (learning from) natural systems, industrial processes can be designed to maximize recycling, minimize throughput, and reduce or eliminate waste output [17].

In a system where there is no waste (i.e. global water and nutrient cycles, the growth of a tree) all byproducts of single processes are picked up as the raw materials of another process. This sharing of what would otherwise be deemed "waste" closes the material loop, increasing both material and energy efficiency. This is particularly true in diverse systems, and often optimization of a larger process or collection of processes is more effective than optimizing a single process or the actions of a single firm [17]. Historical examples of this kind of waste sharing include the US steel industry, in which a significant percentage of scrap would be re-forged rather than discarded, and chemical plants, which regularly make use of process byproducts as seeds for various other processes, either in the same facility or in a neighboring plant [16, 18]. Similarly, cogeneration power plants use the waste heat from the generation of power to heat plant or nearby non-industrial buildings. Eco-industrial parks bring multiple industries together in an intentional symbiosis within which waste products and heat, as well as personnel and information can be shared collectively [19]. Perhaps the best example of an eco-industrial park, the Kalundborg symbiosis in Denmark includes several participants: a chemical plant producing insulin and enzymes; electricity and heat co-generation facility; refinery of petroleum products; producer of gypsum wallboard; microbial soil remediation facility; trout fish farm; and the municipality of Kalundborg [19]. Participants are engaged in 19 different activities involving transfer of water, energy and solid waste. They also are engaged in projects for sharing storage and lab space, creating common contracts with other entrepreneurs, recruiting new employees and locating jobs for spouses.

Korhonen [20] discusses the application of industrial ecology to sustainable development within the context of Strategic Sustainable Development (SSD). In this model, industrial ecology can contribute to definition of principles, identification of the desired state of sustainability and development of tools, as well as implementation and evaluation of actions. In fact, Robert et al [21], authors of the SSD model, argue that with so many approaches, tools and methods for sustainable development the opportunity for contradiction and competition is significant and problematic. Adopting the hierarchical systems 
model provided by SSD allows for the simultaneous and calculated consideration of tools so that they are used as complements rather than as competing approaches. Importantly, and consistent with taking a complex systems approach, the levels are interdependent.

\subsection{Urban metabolism}

Urban metabolism in many ways is simply an extension of the theory behind industrial ecology and studies of industrial metabolism to a specifically urban context. Though subject to a number of different definitions, as a basic concept, urban metabolism provides a way of quantitatively measuring resource inputs and waste outputs - production, consumption, recycling and waste - relative to a city or urban area $[2,22,23]$. It can be thought of as a city's "circulatory system," which processes matter and energy [2]. Huang and Hsu [22] point out the importance of incorporating emergy (or embodied energy) into the analysis. Mitchell [24] accepts these definitions, but proposes a broader concept of urban metabolism as the "social as well as biophysical [means] by which cities acquire or lose the capacity for sustainability in the face of diverse and competing problems." By sustainability he means the maintenance of resources and quality of life in the face of hazards and risk.

Studies measure inputs and outputs within a city or metropolitan area in terms of either mass and/or energy, as well as material recycling. The conversion of diverse physical quantities into units of energy (i.e. joules or solar emjoules, a measure of embodied solar energy in a product or process [22]) allows for more comparison and meaningful gross measures of urban metabolism. A study by Warren-Rhodes and Koenig [23] of the city of Hong Kong built on the pioneering analysis conducted by Newcombe et al [2] in 1978 and showed significant increases in both consumption and waste outputs between 1970 and 1997. The first urban metabolism study conducted on a North American region was completed in Toronto in 2003, suggesting slow development of this concept. The study by Sahely [25] showed that, in general, inputs (consumption) were increasing more rapidly than outputs, suggesting increases in efficiency. Observed residential solid waste and wastewater outflows decreased in real terms over the study period (1987-1999). This is in stark contrast to the results in Hong Kong [23], and may be indicative of the different patterns of urbanization in developed and developing countries.

\subsection{Urban ecology}

Urban ecology is typically approached as either the study of cities in ecosystems or cities as ecosystems [26]. Looking at ecology within cities employs traditional studies of climate, hydrology, soils, flora and fauna, etc. in a defined urban area. Results indicate that spatial heterogeneity is particularly relevant in urban systems [26]. As human-dominated ecological entities, urban areas are characterized by low levels of stability, unique energy dynamics and altered species assemblages [3]. Studies of cities as ecosystems, instead, look at the 
urban area in terms of biogeochemical budgets, ecological footprint [27] and measures of overall species richness. Pickett et al [26] propose a more interdisciplinary approach that joins the two ideas just presented as well as elements from the social sciences. In fact, they point out that the dynamics of social differentiation (hierarchies based on wealth, power, etc.) parallel spatial heterogeneity observed in natural systems, and that consideration of the two systems together can contribute to the understanding of the urban ecosystem as a whole.

Alberti et al [3] come to the same conclusion, but go a step farther and propose a conceptual model that can be used to study explicitly the interactions between human and ecological processes. Depicted in Figure 1, this model identifies forces driving urban development. These drivers define spatial and usage patterns, which in turn impact human and ecological processes. These processes influence more macro-level phenomena such as human behavior and biodiversity, as well as feedback into landscape and social patterns. Completing the loop, acknowledgement of change spurs policy development that comes to act as the driver affecting further alteration of patterns and processes. For example, the provision of water and other infrastructure services beyond city boundaries spurs sprawl development, which affects water quality via increased use of chemical fertilizers (among other reasons), resulting in policy changes affecting future distribution of infrastructure services and therefore development patterns.

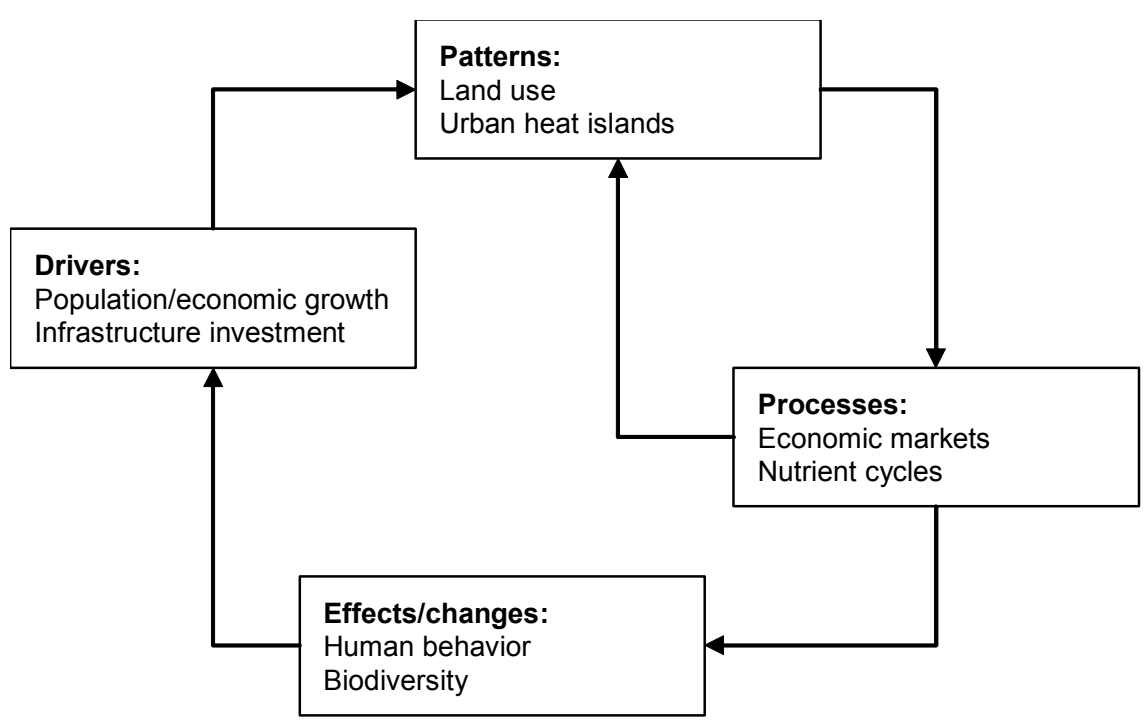

Figure 1: $\quad$ Conceptual model (based on Alberti et al [3]).

The Long Term Ecological Research (LTER) projects currently taking place in Phoenix, Arizona [28] and Baltimore, Maryland [29] are contributing to our understanding of ecology within cities (i.e. fish population dynamics in urban 
streams, regrowth of urban forests) and cities as ecosystems (i.e. ecological footprint, flows of matter and energy). They are actively seeking to define the relationships between human decisions and the landscapes they impact.

\section{Integration and challenges to integration}

In each field discussed above are voices urging for greater integration of social and ecological systems. Taken together, they make an even stronger argument. Both industrial ecology and urban metabolism place the economy (and industry) within a larger social and then biophysical environment [20]. However, analyses of industrial and urban systems have largely focused on physical flows of material and energy, and have not fully engaged the three dimensions of sustainable development - economy, society and environment [20]. In fact, even the most famous realization of an industrial ecosystem, the eco-industrial park at Kalundborg, is ultimately dependent on fossil fuel resources and may not be able to sufficiently adapt to a changing physical and social environment [20]. Similarly, urban ecology and urban metabolism situate the city within a larger context and explicitly account for interactions between human and environmental systems over time and space. These perspectives highlight interdependency and the ultimate physical limits placed on socioeconomic systems by the natural ecosystem.

Industrial ecology and urban metabolism, by focusing on material flows and recycling, seek to increase the efficiency of production and consumption cycles. Thinking of processes on a larger scale opens up opportunities for the reuse of waste products, and system diversity is important. However, technical, economic, organizational, regulatory and legal barriers impede better system design in industrial systems [17]. Political will, corporate and public attitudes also play a major role in either allowing or stifling the development, application and interpretation of novel concepts [16]. To return again to the Kalundborg example, this particular symbiosis developed from the ground up out of a distinct set of existing social linkages. Without such a network - and mutual trust-firms and governments will not be willing to take the risks necessary to alter competitive processes in favor of cooperation [30] nor will they embrace complex and qualitative concepts over traditional quantitative data when making decisions.

The issues of scale (physical, temporal) and perspective (ecological, sociocultural) are critical both for defining system boundaries and subsequent analysis. Research must be holistic as well as focus on individual sectors/ components. Each alone is not sufficient for understanding the functioning of the whole system, and we should constantly strive to look up and down two levels from our primary point of reference [31]. In order to understand more complex systems we need to look above (at a larger organizing system) and below (at components and their behavior) to understand the whole. This requires embracing complexity and dynamics, and accepting uncertainty. A decidedly difficult task, dealing with dynamic systems means planning with change rather than against it, focusing on adaptation and evolution rather than avoidance 
mechanisms. This presents a major challenge for the ecosystem approach. Complex systems, as the name implies, are intricate and their behavior cannot easily be predicted or anticipated. The approach, by necessity, also entails a lack of objectivity that is otherwise expected, and required, of normal science [31]. Boundary definition is subjective, value-laden, and depends on the research question asked. Qualitative as well as quantitative information is also important, underscoring the relevance of political processes and stakeholder involvement in definition and analysis of ecosystems and human interactions with them.

\section{Conclusions}

The ultimate goal of planning should be the attainment of a "healthy city," one constantly learning from past experience in order to improve the quality of life [10]. The search for quality is not a search for static longevity or short-lived functionality, but long term development. However, measurement, especially over the long term, is complicated by a general lack of data (both quantitative and qualitative) describing the interaction of system components. The integration of the disciplines explored in this paper, as well as their application to sustainable development and urban environments is new and underdeveloped. We believe the development, through more integrative research and large-scale experimentation, of a unified urban systems theory will serve to create common ground on which to collect and analyze such information and implement more effective policies.

\section{References}

[1] Population Reference Bureau. Human Population: Fundamentals of Growth: Patterns of World Urbanization, http://www.prb.org/Content/Navigation

Menu/PRB/Educators/Human_Population/Urbanization2/Patterns_of Wo rld Urbanization1.htm.

[2] Newcombe, K., Kalma, J. \& Aston, A. The metabolism of a city: the case of Hong Kong. Ambio, 7, pp. 3-15, 1978.

[3] Alberti, M., Marzluff, J.M., Shulenberger, E., Bradley, G., Ryan, C. \& Zumbrunnen, C., Integrating Humans into Ecology: Opportunities and Challenges for Studying Urban Ecosystems. BioScience, 53(12), pp. 1169-79, 2003.

[4] Vörösmarty, C.J., Green, P., Salisbury, J. \& Lammers, R.B., Global Water Resources: Vulnerability from Climate Change and Population Growth. Science, 289(5477), pp. 284-88, 2000.

[5] Rong, F. Personal communication, 5 April 2006, Ph.D. candidate, University of Maryland, College Park, MD, USA.

[6] Ruth, M., (ed). Smart Growth and Climate Change: Regional Development, Infrastructure and Adaptation, Edward Elgar: New York, 2006. 
[7] Tansley, A.G., The use and abuse of vegetational concepts and terms. Ecology, 16, pp. 284-307, 1935.

[8] Kay, J., Reiger, H., Boyle, M. \& Francis, G., An Ecosystem Approach for Sustainability: Addressing the Challenge of Complexity. Futures, 31(7):721-742, 1999.

[9] Kay, J. \& Schneider, E., Embracing Complexity: The Challenge of the Ecosystem Approach. Alternatives, 20(3), pp. 32-38, 1994.

[10] Ausubel, J.H. \& R. Herman, (eds). Cities and their Vital Systems: Infrastructure-Past, Present and Future, National Academy Press: Washington, DC, 1988.

[11] Walker, B., A Resilience Approach to Sustainable Development, CSIRO Sustainable Ecosystems, and The Resilience Alliance. Unpublished, 2006.

[12] Levin, S.A., Ecosystems and the Biosphere as Complex Adaptive Systems. Ecosystems, 1(5), pp. 431-36, 1998.

[13] Janssen, M., Use of Complex Adaptive Systems for Modeling Global Change. Ecosystems, 1(5), pp. 457-63, 1998.

[14] Rotmans, J., A Complex Systems Approach for Sustainable Cities (Chapter 7). Smart Growth and Climate Change: Regional Development, Infrastructure and Adaptation, ed. Ruth, M., Edward Elgar: New York, pp. 155-180, 2006.

[15] Graedel, T., Industrial Ecology: Definition and Implementation (Chapter 3). Industrial Ecology and Global Change, eds. Socolow, R., Andrews, C., Berkhout, F. \& Thomas, V., Cambridge University Press: Cambridge, pp. 23-41, 1994.

[16] Frosch, R.A. \& Gallopoulos, N.E., Strategies for Manufacturing. Scientific American, September 1989, pp. 144-52, 1989.

[17] Frosch, R.A., Industrial Ecology: Minimizing the Impact of Industrial Waste. Physics Today, November 1994, pp. 63-68, 1994.

[18] Ruth, M., Davidsdottir, B. \& Amato, A., Climate Change Policies and Capital Vintage Effects: The Cases of US Pulp and Paper, Iron and Steel and Ethylene. Journal of Environmental Management, 7(3), pp. 221-233, 2004.

[19] Jacobson, N.B. and S. Anderberg. 2004. Understanding the Evolution of Industrial Symbiotic Networks: The Case of Kalundborg (Chapter 11). Economics of Industrial Ecology, eds. van den Bergh, J.C.J.M. \& Janssen, M.A., The MIT Press: Cambridge, Massachusetts, pp. 313-335.

[20] Korhonen, J., Industrial ecology in the strategic sustainable development model: strategic applications of industrial ecology. Journal of Cleaner Production, 12, pp. 809-23, 2004.

[21] Robert, K.H., Schmidt-Bleek, B., Aloise de Larderel, J., Basik, G., Janson, J.L., Kuehr, R., Price, T.P., Susiki, M., Hawken, P. \& Wackernagel, M. Strategic sustainable development-selection, design and synergies of applied tools. Journal of Cleaner Production, 10, pp. 197-214, 2002.

[22] Huang, S-L. \& Hsu, W-L., Materials flow analysis and emergy evaluation of Taipei's urban construction. Landscape and Urban Planning, 63: 6174, 2003. 
[23] Warren-Rhodes, K. \& Koenig, A., Escalating Trends in the Urban Metabolism of Hong Kong: 1971-1997. Ambio, 30(7), pp. 429-38, 2001.

[24] Mitchell, J.K., Urban metabolism and disaster vulnerability in an era (Chapter X). Earth System Analysis: Integrating Science for Sustainability, eds. Schellnhuber, H-J. \& Wenzel, V., Springer: Berlin, pp. 359-377, 1998.

[25] Sahely, H.R., Dudding, S. \& Kennedy, C.A., Estimating the Urban Metabolism of Canadian Cities: Greater Toronto Area case study. Canadian Journal of Civil Engineering, 30, pp. 468-83, 2003.

[26] Pickett, S.T.A., Cadenasso, M.L., Grove, J.M., Nilon, C.H., Pouyat, R.V., Zipperer, W.C. \& Costanza, R., Urban Ecological Systems: Linking Terrestrial Ecological, Physical, and Socioeconomic Components of Metropolitan Areas. Annual Review of Ecology and Systematics, 32, pp. 127-57, 2001.

[27] Wackernagel, M. \& Rees, W., Our ecological footprint. New Society Publishers: Philadelphia, 1996.

[28] Central Arizona-Phoenix Long-Term Ecological Research (CAP LTER), http://caplter.asu.edu/home/index.jsp.

[29] Baltimore Ecosystem Study, http://www.beslter.org.

[30] Boons, F. \& M.A. Janssen. 2004. The Myth of Kalundborg: Social Dilemmas in Stimulating Eco-Industrial parks (Chapter 12). Economics of Industrial Ecology, eds. van den Bergh, J.C.J.M. \& Janssen, M.A., The MIT Press: Cambridge, Massachusetts, pp. 336-355.

[31] Kay, J.J., The Ecosystem Approach, Ecosystems as Complex Systems and State of the Environment Reporting, Prepared for the North American Commission for Environmental Cooperation, State of the North American Ecosystem Meeting, Montreal 8-10 December, 1994. 